\title{
Penerapan Process Oriented Guided Inquiry Learning Untuk Meningkatkan Keaktifan dan Hasil Belajar Kimia
}

\author{
Banu Kisworo $^{\text {a,1* }}$, Kiki Fatkhiyani ${ }^{\text {b,2 }}$, Empat Patonah ${ }^{\text {a,3 }}$ \\ ${ }^{a}$ Pendidikan kimia, Universitas Muhammadiyah Cirebon \\ ${ }^{\text {b}}$ SMA Muhammadiyah Kedawung Cirebon \\ ${ }^{1}$ kisworo.banu@yahoo.com*, ${ }^{2}$ fatkhiyani@gmail.com, ${ }^{3}$ patonah95@gmail.com \\ *korespondensi penulis
}

\section{Informasi artikel \\ Received : \\ November 29, 2019 \\ Revised : \\ January 17,2019. \\ Publish : \\ January 31, 2020 \\ Kata kunci: \\ process oriented \\ guided inquiry \\ learning, \\ keaktifan, \\ hasil belajar}

\begin{abstract}
ABSTRAK
Penelitian ini bertujuan untuk meningkatkan keaktifan dan hasil belajar kimia peserta didik pada materi hidrokarbon melalui penerapan process oriented guided inquiry learning kelas XI SMA Muhammadiyah Kedawung. Metode penelitian yang digunakan adalah penelitian tindakan kelas yang teridir dari dua siklus, setiap siklus meliputi empat tahapan yakni perencanaan, pelaksanaan, observasi dan refleksi. Instrumen yang digunakan dalam penelitian ini adalah tes uraian untuk mengukur hasil belajar kimia dan lembar observasi untuk megamati keaktifan peserta didik selama proses pembelajaran berlangsung. Hasil penelitian menunjukkan peningkatan keaktifan pembelajaran peserta didik pada proses pembelajaran. Pada kegiatan prasiklus keaktifan peserta didik diperoleh rata-rata skor 41,42 (kriteria rendah), siklus I dengan skor 61,42 (kriteria sedang) dan siklus II dengan skor 78,57 (kriteria tinggi). Hasil belajar peserta didik juga menunjukkan adanya peningkatan dari prasiklus diperoleh rata-rata nilai 63,69 , siklus I sebesar 71,36 dan siklus II sebesar 79,08. Hasil penelitian menunjukkan model process oriented guided inquiry learningdapat meningkatkan keaktifan dan hasil belajar peserta didik kelas XI SMA Muhammadiyah Kedawung Cirebon.
\end{abstract}

\begin{abstract}
This study aims to improve the activeness and learning outcomes of students' chemistry on hydrocarbon material through the application of process oriented guided inquiry learning in eleventh grade Muhammadiyah Kedawung High School. The research method used was classroom action research consisting of two cycles, each cycle containing planning, implementation, observation and reflection. The instrument used in this study was a descriptive test to measure chemistry learning outcomes and an observation sheet to observe the activeness of students during the learning process. The result showed an increase in students' learning activeness in the learning process. In pre-cycle activities, active participants gained an average score of 41,42 (low criteria), cycle I with a score 61,42 (moderate criteria) and cycle II with a score of 78,57 (high criteria). Students' learning outcoes also showed an increase from pre-cycle obtained an average value of 63,69, the first cycle of 71,36 and the second cycle of 79,08. The result showed that the process oriented guided inquiry learning model had increased the activity and learnig outcomes of students in eleventh grade of Muhammadiyah Kedawung Cirebon.
\end{abstract}

Copyright () 2020 (Banu Kisworo, Kiki Fatkhiyani, Empat Patonah). All Right Reserved

How to Cite: Kisworo, B., Fatkhiyani, K., \& Patonah, E. (2020). Penerapan Process Oriented Guided Inquiry Learning Untuk Meningkatkan Keaktifan dan Hasil Belajar Kimia. Jurnal Inspirasi Pendidikan, 10(1), 21-29.

This work is licensed under a Creative Commons Attribution-ShareAlike 4.0 International License. Allows readers to read, download, copy, distribute, print, search, or link to the full texts of its articles and allow readers to use them for any other lawful purpose. The journal hold the copyright. 


\section{Pendahuluan}

Kurikulum 2013 menghendaki proses pembelajaran yang dapat memfasilitasi peserta didik membangun pemahamannya terhadap konsep melalui keterlibatan peserta didik secara aktif selama proses belajar mengajar. Kondisi seperti ini berarti mengarahkan pembelajaran dilakukan melalui proses pembelajaran dilakukan melalui konstruktivisme yang memfasilitasi peserta didik untuk melatihkan keterampilan proses, membangun kemampuan kognitifnya sendiri dan menumbuhkan sikap positifnya. Sains bertujuan untuk mempersiapkan peserta didik terhadap literasi sains dan teknologi. Kimia sebagai bagian dari sains memiliki tujuan yang beriringan dengan tujuan sains tersebut.

Pembelajaran sains di SMA Muhammadiyah Kedawung Cirebon belum sepenuhnya dilaksanakan sesuai dengan proses pembelajaran yang dikehendaki oleh kurikulum. Masih terdapat pembelajaran yang berpusat pada guru (teacher centered) sabagai akibat guru belum menguasai berbagai metode pembelajaran yang variatif, sehingga peserta didik kurang mendapatkan kesempatan untuk menemukan konsep dan mengembangkan kemampun proses berpikir serta hanya sekedar menghafal konsep tanpa memahami dan membuktikan secara empiris. Model pembelajaran di sekolah yang secara umum masih menekankan aspek penerimaan informasi secara penuh dari informasi yang disampaikan oleh guru mengakibatkan keaktifan peserta didik terlihat kurang dalam menggali informasi sendiri. Minat belajar kimia peserta didik yang rendah, membuat guru merasa lebih sulit dalam mengajarkan mata pelajaran kimia dalam proses pembelajaran, akibatnya kegiatan belajar mengajar berlangsung dengan pola pikir peserta didik yang cenderung pasif. Keadaaan tersebut berdampak pada keaktifan peserta didik dan hasil belajar kimia yang menurun.

Keaktifan belajar merupakan bagian yang mendasar dalam keberhasilan proses pembelajaran. Implementasinya dapat di wujudkan dalam kegiatan bersifat fisik maupun mental yakni berpikir, bersikap dan bekerja dalam mencapai tujuan yang diharapkan (Murniasih, 2015). Keberhasilan dalam belajar melibatkan berbagai macam aktifitas baik secara fisik maupun psikis. Aktifitas fisik dilakukan dengan giat aktif dalam mengorganisasikan anggota badan dalam bekerja, melakukan sesuatu dan produktif, jadi tidak hanya mendengarkan, melihat, mencatat atau hanya pasif saja. Sehingga keaktifan peserta didik dalam pembelajaran merupakan kegiatan untuk mengkonstruksi pengetahuan mereka sendiri (Putra \& Purwasih, 2015).

Peserta didik yang aktif dalam pembelajaran akan memiliki pemahaman konsep yang baik, karena mereka akan mengoptimalkan seluruh usahanya dalam belajar. Mereka telah mempersiapkan kegiatan dalam proses pembelajaran. Kegiatan yang ditunjukkan adalah melakukan pengamatan, mencari literature, berpikir kreatif, berpikir kritis, mengkomunikasikan hasil pemikirannya sendiri, serta dapat berpikir reflektif. Apabila peserta didik giat berusaha dalam melakukan kegiatan tersebut maka akan memperoleh hasil belajar yang baik dan efektif.

Solusi yang penting untuk kendala-kendala tersebut adalah penggunaan model pembelajaran yang efektif dan sesuai dengan pradigma konstruktivisme dalam meningkatkan keaktifan serta hasil belajar peserta didik. Model pembelajaran yang dimaksud adalah model Process Oriented Guided Inquiry Learning. Dalam penerapannya dapat menumbuhkan keaktifan peserta didik, membuat peserta didik aktif dalam proses pembelajaran sehingga akan berdampak pada peningkatan hasil belajar kimia peserta didik.

Model pembelajaran POGIL merupakan pembelajaran inkuiri yang berorientase proses dan berpusat pada peserta didik, maka dapat dikatakan bahwa Process Oriented Guided Inquiry Learning (POGIL) merupakan suatu starategi yang memungkinkan guru mengajarkan konsep materi dan keterampilan proses secara bersamaan. (POGIL) merupakan Perpaduan 
pembelajaran kooperatif dan aktivitas penyelidikan terbimbing yang dapat memberi kesempatan kepada peserta didik untuk aktif dalam kelompok diskusi untuk mengkonstruksi pemahaman mereka (Kisworo, Banu. Gusman, 2019). Pembelajaran POGIL meningkatkan keaktifan peserta didik akan pentingnya kerja kelompok, tentang pentingnya rekan-rekan mereka dalam membantu mereka untuk memahami konsep-konsep (Sona, 2016). Tugas dan peran anggota kelompok heterogen yang dibentuk dalam kegiatan POGIL bertujuan meningkatkan pengembangan keterampilan proses kerja sama tim (Spencer \& Moog, 2007).

Kelebihan POGIL didukung oleh beberapa hasil penelitian yang telah dilakukan sebelumnya. PLTL (Peer-led Team Learning), PBL (Problem Based Learning) dan POGIL (Process Oriented Guided Inquiry Learning) membuktikan bahwa POGIL dapat meningkatkan kinerja, hasil belajar, dan guru menemukan lingkungan kelas yang lebih menyenangkan (Hanib, SUhadi, \& Indriwati, 2017). Pembelajaran model POGIL dapat melatih kemampuan berpikir kritis peserta didik (Malik, Oktaviani, Handayani, \& Chusni, 2017).

\section{Metode}

Jenis penelitian ini adalah penelitian tindakan kelas (PTK)yang bertujua untuk menyelesaikan permasalahan yang dihadapi peserta didik pada materi Hidrokarbondengan menggunakan model Process Oriented Guided Inquiry Learning (POGIL). Penelitian ini terdiri atas beberapa tahapan, yakni (a) observasi awal ubtuk mengidentifikasi permasalahan awal; (b) merencanakan pembelajaran untuk memperbaiki permasalahan dalam pembelajaran dengan disertai pembuatan perangkat pembelajaran dan instrumen penelitian; (c) melaksanakan pembelajaran secara langsung; (d) mengumpulkan data penelitian yang berkaitan dengan validasi perangkat pembelajaran, hasil pembelajaran, hasil observasi dan hasil wawancara dengan peserta didik; (e) menganalisis data yang diperoleh; (f) menyusun laporan penelitian.

Subjek penelitian adalah kelas XI IPA SMA Muhammadiyah Kedawung Cirebon Tahun Pelajaran 2019/ 2020 berjumlah 25 peserta didik. Data yang dikumpulkan dalam penelitian meliputi instrumen penelitian, hasil observasi keaktifan peserta didik, hasil penilaian belajar peserta didik. Analisis data dilakukan secara kuantitaif dan kualitatif pada akhir siklus. Analisis data secara kuantitatif diperoleh dari data observasi keaktifan peserta didik dan data hasil belajar peserta didik. Setelah data hasil pengamatan keaktifan diperoleh maka selanjutnya direkap dan dikonversi dalam bentuk prosentase keaktifan dengan menggunakan rumus :

Keterangan :

$$
\operatorname{PSA}(\%)=\left(\frac{S a}{S m a x}\right) \times 100 \%
$$

PSA (\%) : Prosentase skor keaktifan peserta didik

Sa $\quad$ : Skor keaktifan yang diperoleh mahasiswa

Smax : Skor keaktifan Maksimal

Kriteria yang digunakan dalam menentukan hasil pengamatan indicator keaktifan yaitu:

$\begin{array}{ll}85 \%<\mathrm{PSA}(\%) \leq 100 \% & \text { Keaktifan sangat tinggi } \\ 70 \%<\mathrm{PSA}(\%) \leq 85 \% & \text { Keaktifan tinggi } \\ 50 \%<\mathrm{PSA}(\%) \leq 70 \% & \text { Keaktifan sedang } \\ 0 \%<\mathrm{PSA}(\%) \leq 50 \% & \text { Keaktifan rendah }\end{array}$


Instrumen pengumpulan data yang digunakan adalah tes essay Sedangkan data hasil belajar kimia yang diperoleh dapat ditentukan dengan menggunakan rumus :

$$
\text { Nilai Total Akhir (NT) }=\frac{\text { Nilai yang diperoleh siswa (NA) }}{\text { Nilai maksimal siswa (NS) }} \times 100 \%
$$

Hasil analisis data tersebut dapat digunakan untuk menentukan ketuntasan proses dan hasil belajar. Penelitian dapat dikatakan tuntas jika $80 \%$ peserta didik memproleh skor Keaktifan belajar melampaui skor 3,00.dan $80 \%$ peserta didik hasil tes akhirnya melampaui nilai 70. Sedangkan alur penelitian tindakan kelas ini dapat digambarkan melalui Diagram siklus penelitian tindakan kelas disajikan pada gambar berikut .

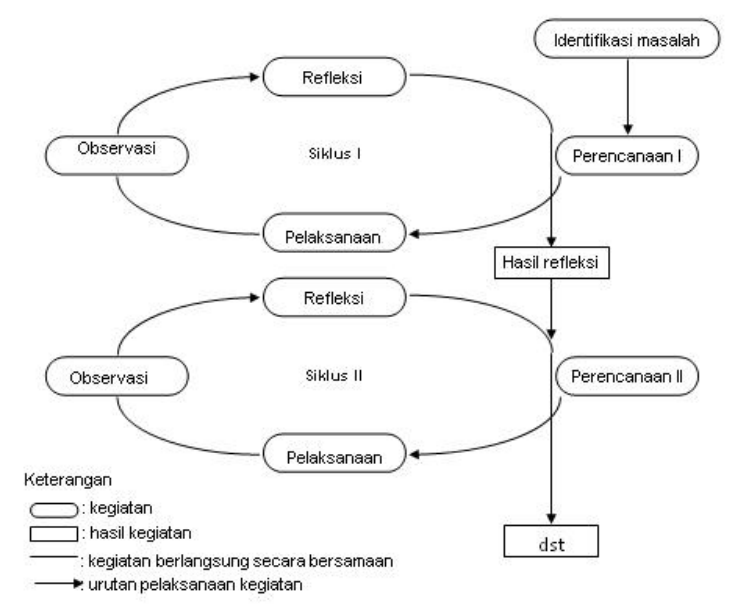

Gambar 1. Siklus Penelitian Tindakan Kelas (Kemmis, McTaggart, \& Nixon, 2014)

\section{Hasil dan pembahasan \\ Hasil Penelitian}

Analisis data hasil belajar peserta didik disajikan pada table berikut.

Tabel 1. Hasil belajar Peserta didik

\begin{tabular}{lccc}
\hline & Prasiklus & Siklus I & Siklus II \\
\hline Nilai Maks & 77,14 & 85,71 & 94,28 \\
Nilai Min & 40,00 & 51,42 & 62,85 \\
Sdv & 13,03 & 10,55 & 7,75 \\
Rata-rata & 63,69 & 71,36 & 79,08 \\
\% lulus kkm & $32 \%$ & $60 \%$ & $80 \%$ \\
\hline
\end{tabular}

Berdasarkan tabel 1 diatas dapat dijelaskan bahwa rata-rata tiap siklus mengalami peningkatan rerata dan prosentase lulus kkm dari pra siklus, siklus 1 sampai siklus 2 sebesar $20-28 \%$. 


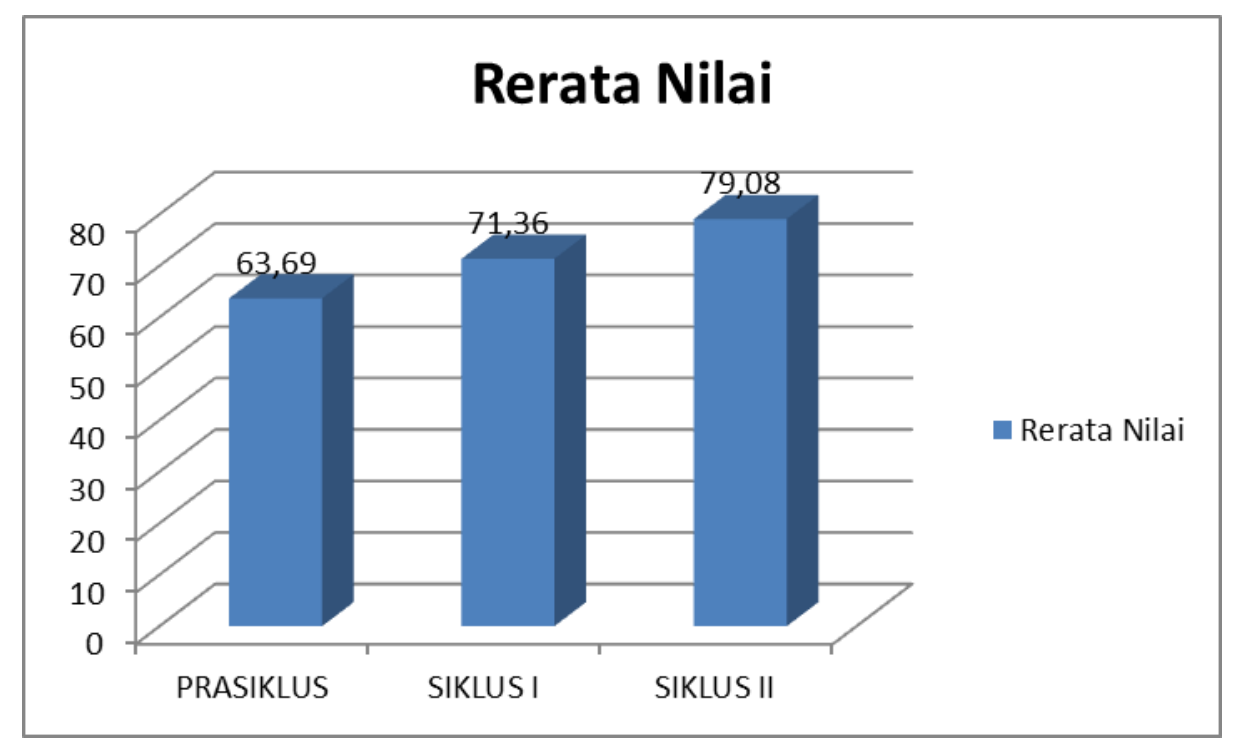

Gambar 2. Grafik peningkatan rata-rata hasil belajar tiap siklus

Berdasarkan gambar 2 diatas, menunjukkan grafik peningkatan rerata hasil belajar peserta didik dari pra siklus sampai dengan siklus 1 sebesar 7,67, dan untuk siklus 1 sampai dengan siklus 2 terdapat peningkatan sebesar 7,72. Hal tersebut menunjukkan bahwa model pembelajaran POGIL berhasil meningkatkan hasil belajar peserta didik.

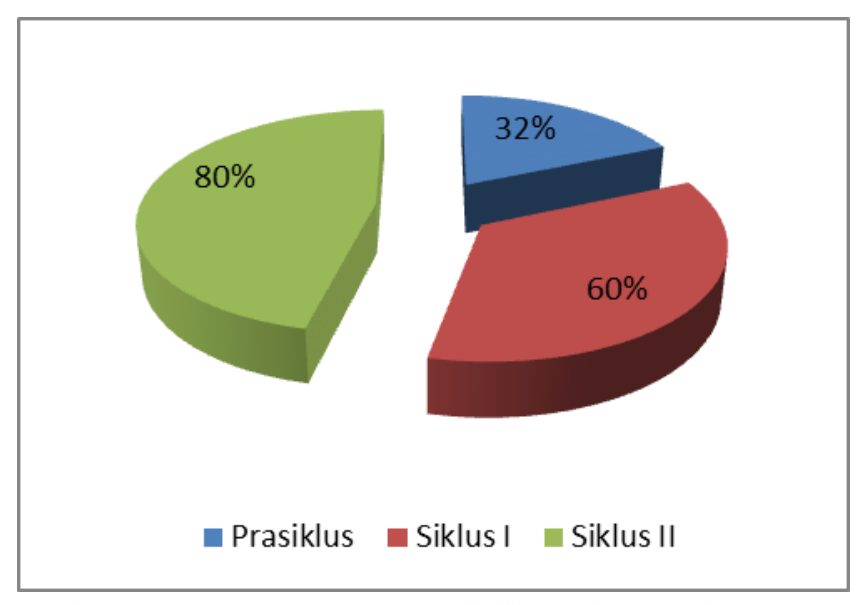

Gambar 3. Prosentase peserta didik melampaui KKM

Berdasarkan diagram diatas menunjukkan bahwa prosentase peserta didik melampaui nilai $\mathrm{kkm}$ prasiklus hanya $32 \%$ peserta didik yang melampaui $\mathrm{kkm}$, selanjutnya pada siklus I terdapat peningkatan sebesar $28 \%$, kemudian pada siklus 2 terdapat peningkatan lagi sebesar $20 \%$. Hal tersebut menunjukkan bahwa penerapan model POGIL berhasil membuat peserta didik berhasil melampaui nilai kkm.

Berikut hasil skor keaktifan peserta didik pada saat proses pembelajaran menggunakan model pembelajaran POGIL disajikan pada tabel berikut. 
Jurnal Inspirasi Pendidikan, VOL.10, NO.1, Edisi Januari 2020

Penerapan Process Oriented Guided Inquiry Learning untuk Meningkatkan Keaktifan dan Hasil Belajar

Kimia

Banu Kisworo ${ }^{1}$, Kiki Fatkhiyani ${ }^{2}$, Empat Patonah ${ }^{3}$

Hal: 21-29

Tabel 2. Skor keaktifan peserta didik

\begin{tabular}{cccc}
\hline & Prasiklus & Siklus I & Siklus II \\
\hline Skor maks & 58,45 & 77,15 & 85,45 \\
\hline Skor min & 37,25 & 54,65 & 73,88 \\
\hline Sdv & 14,96 & 15,90 & 8,18 \\
\hline Rata-rata skor (kriteria) & 41,42 (rendah) & 61,42 (sedang) & 78,57 (tinggi) \\
\hline
\end{tabular}

Berdasarkan tabel 2 menunjukkan terdapat peningkatan skor keaktifan siswa dari prasiklus sampai dengan siklus 1 terdapat peningkatan skor keaktifan peserta didik sebesar 20, dan untuk siklus I sampai dengan siklus 2 terdapat peningkatan skor sebesar 17, 15. Hal tersebut menunjukkan bahwa model pembelajaran POGIL dapat menstimulus keaktifan peserta didik dalam mengikuti proses pembelajaran.

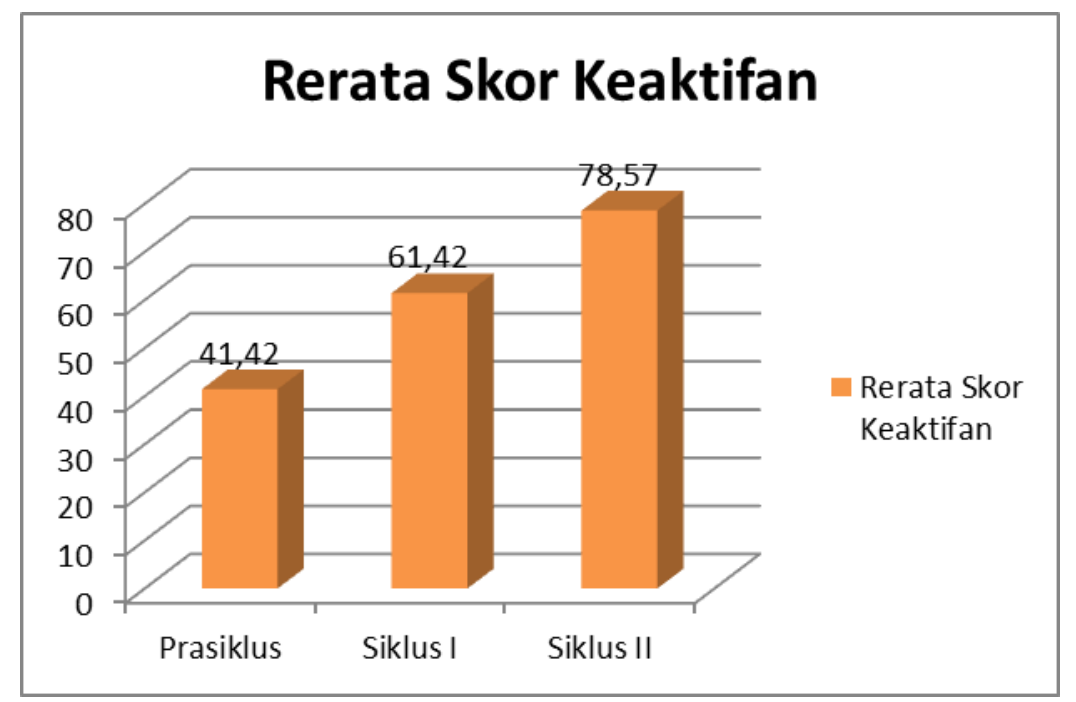

Gambar 4. Grafik Keaktifan peserta didik

Gambar diatas menunjukkan peningkatan keaktifan peserta didik yang mengalami peningkatan pada setiap siklus, dari pra siklus ke siklus 1 dengan skor sebesar 20, dan dari siklus 1 ke siklus 2 terjadi peningkatan sebesar 17,16.

\section{Pembahasan}

Pembelajaran POGIL dalam penelitian ini terbukti meningkatkan keaktifan serta hasil belajar dimulai pada tahap para siklus sampai dengan siklus ke-2. Pembelajaran POGIL memberikan kesempatan kepada peserta didik untuk membangun pengetahuan mereka sendiri dengan guru yang berfungsi sebagai fasilitator, dalam hal ini pembelajaran berpusat kepada peserta didik, sedangkan guru berfungsi sebagai penyedia materi, sekaligus pemandu dengan menitikberatkan peserta didik yang terlebih dahulu telah diberikan stimulus untuk mendalami materi, menerima indikasi, sehingga mereka dapat menemukan pengetahuan itu sendiri dan semua materi yang mereka dapat harus terbukti secara ilmiah. Hal tersebut sesuai dengan hasil penelitian yang dilakukan oleh Vanags, yang menyatakan bahwa pendekatan POGIL dapat menghasilkan hasil belajar jangka panjang yang lebih baik, peserta didik menjadi lebih percaya diri membangun pengetahuan mereka, karena mereka tidak hanya membangun pengetahuan dengan hanya berkutat pada materi tetapi mereka juga harus 
Jurnal Inspirasi Pendidikan, VOL.10, NO.1, Edisi Januari 2020

Penerapan Process Oriented Guided Inquiry Learning untuk Meningkatkan Keaktifan dan Hasil Belajar

Kimia

Banu Kisworo $^{1}$, Kiki Fatkhiyani ${ }^{2}$, Empat Patonah $^{3}$

menerima indikasi bahwa pengetahuan yang mereka bangun adalah valid, sehingga mereka dapat belajar bertanggung jawab dari pembelajaran yang mereka dapatkan dan menjadi jaminan bahwa representasi mental adalah akurat yang merupakan landasan untuk ingatan yang panjang dan kepercayaan dari pengetahuan yang mereka bangun (Vanags, Pammer, \& Brinker, 2013).

Dari pendekatan ini peserta didik memiliki harapan, bahwa mereka akan diajarkan oleh seorang yang berpengalaman. Berarti, penting bagi seorang pengajar untuk memberikan umpan balik yang tepat kepada peserta didik, sehingga mereka merasa bahwa guru merupakan bagian dari pembelajaran mereka, dengan cara memberikan alasan dan memulai diskusi seluruh kelas tentang penggunaan POGIL membantu mereka lebih aktif dan lebih memahami pembelajaran mereka. Namun, dalam waktu yang bersamaan, guru tidak boleh lupa untuk berhati - hati mengarahkan mereka untuk menemukan konsep sendiri dan menunjukkan kemampuan mereka (Douglas \& Chiu, 2012).

Pendekatan POGIL dilakukan dengan mendistribusikan paket kerja peserta didik yang digunakan untuk pelatihan dan penguatan materi yang sudah difasilitasi oleh guru, di dalamnya terdapat intruksi untuk mengikuti kegiatan pembelajaran dan evaluasi yang akan dipandu oleh guru. Peserta didik diwajibkan mengikuti panduan, sehingga mereka dapat berperan aktif mempelajari konsep materi dasar, sampai dengan pertanyaan - pertanyaan pemikiran kritis yang guru berikan pada akhir sesi agar mereka dapat membangun pengetahuannya sendiri (Jaffe, Gibson, \& D’Amico, 2015). Dalam penelitian ini penulis menggunakan paket kerja berupa LKPD (lembar Kerja Peserta Didik). Format materi yang disampaikan dalam siklus pembelajaran POGIL dimulai dari : (1) mengeksplor ide - ide baru dengan membandingkan pengetahuan sebelumnya, (2) peserta didik menemukan konsep pengetahuan untuk diri mereka sendiri yang sesuai dengan konteks materi yang ada dalam pertanyaan dan terakhir (3) konsep materi tersebut sesuai dengan fakta yang ada (Hanson M. David, 2006). Sejalan dengan penelitian Hanson, dalam pembelajaran peserta didik dengan menggunakan LKPD, ada beberapa langkah yang dilakukan yaitu : (1) peserta didik mengeksplor materi hydrocarbon seperti mengembangkan pengetahuan apa yang menyebabkan proses pembakaran yang berbeda pada setiap jenis bahan bakar seperti bensin, kerosin, solar, pertalite dan pertamax, apa yang membuat harga setiap bahan bakar itu berbeda, dengan berdasarkan pada pengetahuan sebelumnya mengenai atom - atom karbon yang membentuk rantai - rantai yang nantinya membentuk pola yang disebut alkana, alkena dan alkuna. (2) sehingga mereka menemukan konsep pengetahuan mereka penggolongan pola senyawa hidrokarbon berdasarkan pembentukan rantai - rantai atom karbon. (3). Akhirnya mereka mengetahui bahwa materi yang mereka pelajari mengenai senyawa hidrokarbon kontekstual dengan kehidupan kita sehari-hari.

Pembelajaran dengan menggunakan pendekatan POGIL mengurangi penggunaan kertas, sehingga memudahkan guru untuk menambahkan langkah - langkah dalam memberikan informasi, sehingga kecepatan kegiatan dapat diatur. Di akhir pembelajaran, peserta didik diminta untuk menjelaskan pengalaman mereka secara singkat, awalanya mereka tidak yakin dengan pendekatan ini karena baru mereka kenal, tetapi kemudian mereka menyadari bahwa mereka telah menguasai konsep dan keterampilan proses. Ketika peserta didik kurang memahami bahasa instruktur, peserta didik yang telah dibagi dalam beberapa kelompok kemudian menerjemahkan dengan bahasa yang mereka pahami dalam bentuk aktivitas diskusi, dengan mendatangi kelompok lain untuk sharing terkait tema, dan kami dapat saling memperbaiki pemahaman informasi yang diterima (Kussmaul, 2012). Berdasarkan penelitian tersebut pendekatan POGIL membuat peserta didik dipacu untuk aktif dalam kegiatan pembelajaran, mereka lebih banyak interaksi dengan berdiskusi terkait 
konsep materi yang mereka pelajari, ketimbang pembelajaran konvensional yang lebih banyak menggunakan kertas untuk menjawab soal dan membuat ataupun menganalisis materi yang disampaikan. Dalam pendekatan ini peserta didik dapat mengemukakan pendapatnya dengan lugas, dan jika terdapat kesalahan mereka harus siap menerima kritikan agar mereka dapat membangun pengetahuan mereka sendiri secara valid. Hal tersebut tentunya sesuai dengan apa yang dilakukan oleh peneliti dimana pendekatan POGIL dapat meningkatkan keaktifan siswa dengan peningkatan skor antara $17-20$ antar siklusnya, dengan demikian apa yang peneliti lakukan didukung oleh peneliti sebelumnya.

Selain meningkatkan keaktifan peserta didik, pendekatan POGIL juga dapat meningkatkan hasil belajar (Hunnicutt, Grushow, \& Whitnell, 2015). Mereka melakukan penelitian mengenai proyek POGIL-pada praktikum Kimia Fisika untuk menerapkan prinsip - prinsip pembelajaran yang berdasarkan pada proses, dengan landasan POGIL untuk meningkatkan pembelajaran mahasiswa dalam mata praktikum kimia fisika. Percobaan kimia fisika dengan berlandaskan telaah eksperimen yang dikembangkan dengan mengacu kepada berbagai fenomena kimia. Dalam penelitian ini, mahasiswa melakukan kegiatan seperti membuat prediksi, pengumpulan data, membuat model data, dan melakukan diskusi terkait hasil praktikum tersebut, sehingga mereka dapat menentukan kesimpulan dari percobaan yang telah dilakukan. Mereka menentukan parameter mana yang tepat dimodifikasi dalam percobaan berikutnya dari percobaan yang sama, sebagai contoh: "Parameter kinetik apa yang digunakan dari reaksi heterogen". Hasil dari penelitian menunjukkan peningkatan pemahaman konseptual (hasil belajar), terampil dalam pengambil keputusan terkait langkah yang dilakukan dalam kegiatan praktikum, dan lebih kreaktif dan mandiri di laboratorium. Penelitian tersebut memberikan gambaran mengenai pendekatan POGIL tepat digunakan untuk meningkatkan hasil belajar, karena dalam melakukan eksperimen dengan menggunakan pendekatan POGIL, mahasiswa terlatih untuk melakukan kegiatan saintifik yang dari membuat prediksi sampai dengan menyimpulkan. Douglas \& Chiu (2012), menambahkan bahwa dengan pendekatan ini peserta didik secara aktif terlibat dalam memproses informasi dan memiliki kesempatan untuk memanfaatkan dan mengembangkan keterampilan penting seperti kerja tim, komunikasi, dan pemikiran kritis, ke-tiga komponen tersebutlah yang membuat pendekatan ini dapat meningkatkan keaktifan serta hasil belajar peserta didik.

\section{Simpulan}

Pembelajaran berbasis POGIL (Process Oriented Guided Inquiry Learning) memberikan kesempatan kepada peserta didik agar dapat membangun pengetahuan mereka sendiri, melalui beberapa kegiatan saintifik, dimulai dari kegiatan memprediksi, menanya, menghubungkan, menginferensi dan menyimpulkan yang dilakukan melalui diskusi antar kelompok, dengan saling memberikan tanggapan secara kritis dan siap untuk menerima kritik apabila konsep yang mereka temukan salah, agar didapat konsep materi yang valid, sehingga kemampuan peserta didik untuk aktif dalam kegiatan pembelajaran meningkat. Peningkatan keaktifan proses pembelajaran akan sejalan dengan peningkatan hasil belajar peserta didik, karena kemampuan kognitif, dan psikomotorik mereka terasah secara langsung sehingga mereka menemukan sendiri konsep yang mereka pelajari dengan fungsi guru hanya sebagai fasilitator dan pembimbing yang tetap memberikan umpan balik kepada peserta didik sehingga mereka merasa bahwa guru juga merupakan bagian dari proses pembelajaran yang mereka lakukan.

\section{Referensi}


Jurnal Inspirasi Pendidikan, VOL.10, NO.1, Edisi Januari 2020

Penerapan Process Oriented Guided Inquiry Learning untuk Meningkatkan Keaktifan dan Hasil Belajar

Kimia

Banu Kisworo $^{1}$, Kiki Fatkhiyani ${ }^{2}$, Empat Patonah $^{3}$

Hal: 21-29

Douglas, E. P., \& Chiu, C.-C. (2012). Process-oriented Guided Inquiry Learning in Engineering. Procedia - Social and Behavioral Sciences. https://doi.org/10.1016/j.sbspro.2012.09.652

Hanib, M. T., SUhadi, \& Indriwati, S. E. (2017). Penerapan Pembelajaran Process Oriented Guided Inquiry Learning Untuk Meningkatkan Kemampuan Berpikir Kritis Dan Karakter Siswa Kelas X. Pendidikan.

Hanson M. David. (2006). Instructor's Guide to Process-Oriented Guided-Inquiry Learning. Pacific Crest.

Hunnicutt, S. S., Grushow, A., \& Whitnell, R. (2015). Guided-inquiry experiments for physical chemistry: The POGIL-PCL model. Journal of Chemical Education. https://doi.org/10.1021/ed5003916

Jaffe, L., Gibson, R., \& D'Amico, M. (2015). Process-oriented guided-inquiry learning: A natural fit for occupational therapy education. Occupational Therapy in Health Care. https://doi.org/10.3109/07380577.2015.1010030

Kemmis, S., McTaggart, R., \& Nixon, R. (2014). The Action Research Planner. In The Action Research Planner. https://doi.org/10.1007/978-981-4560-67-2

Kisworo, Banu. Gusman, T. (2019). Process oriented guided inquiry learning to increase student' $s$ critical thinking ability on chemistry learning at Islamic High School in Cirebon Process Oriented Guided Inquiry Learning to Increase Student's Critical Thinking Ability on Chemistry Lear. AIP, 020050. Retrieved from https://aip.scitation.org/doi/abs/10.1063/1.5139782

Kussmaul, C. (2012). Process Oriented Guided Inquiry Learning (POGIL) for computer science. SIGCSE'12 - Proceedings of the 43rd ACM Technical Symposium on Computer Science Education. https://doi.org/10.1145/2157136.2157246

Malik, A., Oktaviani, V., Handayani, W., \& Chusni, M. M. (2017). Penerapan Model Process Oriented Guided Inquiry Learning (POGIL) untuk Meningkatkan Keterampilan Berpikir Kritis Peserta Didik. Jurnal Penelitian \& Pengembangan Pendidikan Fisika. https://doi.org/10.21009/1.03202

Murniasih, T. R. (2015). Summary for Policymakers. Jurnal Inspirasi Pendidikan, 5(2), 691697. https://doi.org/10.21067/jip.v5i2.806

Putra, H. D., \& Purwasih, R. (2015). Meningkatkan Prestasi Belajar Dan Keaktifan Mahasiswa Melalui Project Based Learning. P2M STKIP Siliwangi, 2(2), 128. https://doi.org/10.22460/p2m.v2i2p128-136.156

Spencer, J. N., \& Moog, R. S. (2007). The Process Oriented Guided Inquiry Learning Approach to Teaching Physical Chemistry. https://doi.org/10.1021/bk-2008-0973.ch016

Vanags, T., Pammer, K., \& Brinker, J. (2013). Process-oriented guided-inquiry learning improves long-term retention of information. American Journal of Physiology Advances in Physiology Education. https://doi.org/10.1152/advan.00104.2012 